\title{
Predicting the population dynamics of the house dust mite Dermatophagoides pteronyssinus (Acari: Pyroglyphidae) in response to a constant hygrothermal environment using a model of the mite life cycle
}

\author{
Phillip Biddulph ${ }^{1,5}$, David Crowther ${ }^{1}$, Brian Leung ${ }^{2}$, Toby Wilkinson ${ }^{1,3}$, Barbara \\ Hart $^{4}$, Tadj Oreszczyn ${ }^{5}$, Stephen Pretlove ${ }^{6}$, Ian Ridley ${ }^{5}$, Marcella Ucci ${ }^{5}$ \\ ${ }^{1}$ The Martin Centre, University of Cambridge, 1 Scroope Terrace, Cambridge CB2 1PX, UK \\ ${ }^{2}$ Biology Department, McGill University, 1205 Docteur Penfield, Montreal, Quebec H3A 1B1, Canada \\ ${ }^{3}$ Medical Entomology Centre, Barrington Road, Shepreth, Royston SG8 6QZ, UK \\ ${ }^{4}$ Royal Agricultural College, Stroud Road, Cirencester, Gloucestershire, GL7 6JS,UK \\ ${ }^{5}$ The Bartlett School of Graduate Studies, University College London, WC1E 6BT, UK \\ ${ }^{6}$ Kingston University, School of Architecture \& Landscape, London, KT1 2QJ, UK \\ Corresponding author: Phillip Biddulph \\ Email: p.biddulph@ucl.ac.uk \\ Telephone: ++020 76791643 \\ Fax: ++02079161887
}




\begin{abstract}
A generalised model of the life cycle of a house dust mite, which can be tailored to any particular species of domestic mite, is presented. The model takes into account the effects of hygrothermal conditions on each life cycle phase. It is used in a computer simulation program, called POPMITE, which, by incorporating a population age structure, is able to predict population dynamics.
\end{abstract}

The POPMITE simulation is adapted to the Dermatophagoides pteronyssinus (Acari: Pyroglyphidae) (DP) mite using published data on the egg development period, total development period, adult longevity, mortality during egg development, mortality during juvenile development, and fecundity of individual DP mites held at a range of constant hygrothermal conditions.

An example is given which illustrates how the model functions under constant hygrothermal conditions.

A preliminary validation of POPMITE is made by a comparison of the POPMITE predictions with published measurements of population growth of DP mites held at a range constant hygrothermal conditions for 21 days.

The POPMITE simulation is used to provide predictions of population growth or decline for a wide range of constant relative humidity and temperature combinations for 30 and 60 days.

The adaptation of the model to correctly take account of fluctuating hygrothermal conditions is discussed.

\title{
Keywords
}

House dust mites, population model, relative humidity, temperature, life cycle, population structure 


\section{Introduction}

The house dust mite Dermatophagoides pteronyssinus (Acari: Pyroglyphidae) (DP) is one of several species giving rise to allergens that play a major role in allergic disease, especially asthma (Voorhorst et al. 1969 and Ford et al. 1985). DP is the most common species of house dust mite in the UK, and is predominant in many countries around the world (Bronswijk 1981 and Colloff 1998). Their major habitats are beds, carpets and soft furnishings.

Mites have few natural predators, so that in a typical habitat the principal limits on the population size are the available food and the hygrothermal environment, which can be described by the relative humidity (RH) and the temperature (T) (Bronswijk 1981). In this paper we make the simplifying assumption that food is plentiful and is not limiting the population size.

Predicting the population dynamics in the hygrothermal conditions of the habitat is a crucial step in the study of different strategies for controlling mite populations, and therefore the production of allergen (see Crowther et al. 2006). Past, present and simulated future climate data can be used in conjunction with building simulations (for example see EnergyPlus 2004) to predict the internal climate of bedrooms for a wide range of house types and conditions, as well as different occupant behaviour regimes. These predictions or actual measurements can be used in turn to predict the internal conditions of beds (Pretlove et al. 2005).

An accurate computer simulation of the population dynamics of dust mites is needed to complement the range of simulations available to predict the environment of the habitat. The suite of simulations can then be used to test scenarios for controlling dust mite populations in beds. Small changes in occupant behaviour or building design may have a significant effect on the population dynamics.

Previous attempts to model the population dynamics by Cunningham (2000) and more recently Crowther et al. (2006) have used the simplifying assumption that there exists a population growth multiplication factor which is constant for a particular $\mathrm{RH}$ and $\mathrm{T}$ combination, regardless of the structure of the population. Whilst these models have the advantage of being easy to implement they can lead to misleading results even during periods of constant conditions. For example a population of pure eggs is unable to grow until at least one mating pair has matured and as a population develops the numbers of egg laying females will fluctuate naturally. This would lead to fluctuating rates of population growth, which would cause problems for these models, both in terms of calibration and use. To overcome them a model which can keep track of the population structure has been developed.

Mites develop through various life phases, from eggs to juveniles (larvae, protonymphs and tritonymphs for DP) to adults. Mites at each phase of the life cycle have different development times and mortalities depending on the hygrothermal conditions (Gamal Eddin et al. 1983a,c). The fecundity of female adults also depends on the hygrothermal conditions (Gamal Eddin et al. 1983b).

The population dynamics of dust mites is most sensitive to the parameters described above. As with any model, this model uses simplifying assumptions, particularly for the less sensitive parameters (e.g. the age dependence of the egg laying rate). A preliminary validation of the model indicates that these assumptions are acceptable.

A generalised model of the life cycle of a house dust mite, using information on development times and mortalities, can be tailored to any particular species of domestic mite. The age structure of the mite population can be simulated by keeping track of the development and numbers of mites in batches as they progress through the life cycle model.

In this way a computer simulation program able to predict population dynamics, called POPMITE, has been constructed that incorporates the life cycle model and a population age structure. POPMITE has been tailored to DP mites using a selection of published data describing their physiological response to a range of constant hygrothermal conditions. 
Nomenclature

The following table lists the symbols, their meanings and units as used throughout this paper.

\begin{tabular}{|c|c|c|}
\hline Symbol & Meaning & Units \\
\hline $\mathrm{T}$ & Temperature & ${ }^{\circ} \mathrm{C}$ \\
\hline $\mathrm{RH}$ & Relative humidity & $\%$ \\
\hline $\mathrm{t}$ & Time slice & hour \\
\hline $\mathrm{N}_{\text {egg }}$ & Number of eggs & eggs \\
\hline $\mathrm{N}_{\text {juvenile }}$ & Number of juveniles & juveniles \\
\hline $\mathrm{N}_{\text {adult }}$ & Number of adults & adults \\
\hline $\mathrm{D}_{\text {egg }}$ & Egg development duration & ours \\
\hline $\mathrm{D}_{\text {juvenile }}$ & Juvenile development duration & hours \\
\hline $\mathrm{D}_{\text {adult }}$ & Adult longevity & hours \\
\hline $\mathrm{R}_{\text {egg }}$ & Egg Percentage Development rate & $\% /$ hour \\
\hline $\mathrm{R}_{\text {juvenile }}$ & Juvenile Development rate & $\% /$ hour \\
\hline $\mathrm{R}_{\text {adult }}$ & Adult Ageing rate & $\% /$ hour \\
\hline $\mathrm{d}_{\text {egg }}$ & Percentage development of eggs & $\%$ \\
\hline $\mathrm{d}_{\text {juvenile }}$ & Percentage development of juveniles & $\%$ \\
\hline $\mathrm{d}_{\text {adult }}$ & Percentage development of adults & $\%$ \\
\hline $\mathrm{M}_{\mathrm{egg}}$ & Total mortality during the egg phase. & $\%$ \\
\hline $\mathrm{M}_{\text {juvenile }}$ & Total mortality during the juvenile phases. & $\%$ \\
\hline $\mathrm{M}_{\text {adult }}$ & Total mortality during the adult phase. & $\%$ \\
\hline $\mathrm{S}_{\text {egg }}$ & Egg survivability, the probability of surviving until hatching. & \\
\hline S $_{\text {juvenile }}$ & $\begin{array}{l}\text { Juvenile survivability, the probability of a freshly hatched juvenile surviving } \\
\text { until moulting into an adult. }\end{array}$ & \\
\hline $\mathrm{S}_{\text {adult }}$ & Adult survivability, the probability of surviving the natural adult life span. & \\
\hline $\mathrm{S}_{\text {egg }}$ & Egg hourly survival probability & hour $^{-1}$ \\
\hline $\mathrm{S}_{\text {juvenile }}$ & Juvenile hourly survival probability & hour $^{-1}$ \\
\hline $\mathrm{S}_{\text {adult }}$ & Adult hourly survival probability & hour $^{-1}$ \\
\hline$F$ & Egg laying rate of adult female mites. & eggs/hour \\
\hline$f$ & $\begin{array}{l}\text { Fecundity or the mean number of eggs produced per female mite during her } \\
\text { adult life. }\end{array}$ & eggs \\
\hline
\end{tabular}




\section{Theory}

The methods for calculating the population dynamics described here are similar to those that use the Leslie matrix model (Leslie 1945) as described by Nisbet and Gurney (1982) and Case (2000).

If the initial structure of a population of mites (numbers and ages of eggs, juveniles and adults) is known, then our aim is to predict the change in the structure after a short period of constant hygrothermal conditions. This can be done by calculating:

- the increase in development and the loss of mites for each of the life cycle phases separately, and

- the number of freshly laid eggs.

By repeating this process over many time periods one can thus predict the population dynamics.

A population of mites will consist of batches of individuals at any one of the phases of their life cycle. Each batch will be at a unique development stage within the phase and will be progressing through the phase at a rate which depends on the hygrothermal environment. The environment will also play a role in determining the chances of survival and the rate at which adult females lay eggs. The physiological response of mites in a particular phase to the constant conditions can be described by:

- the percentage development rate $(\mathrm{R})$,

- the survival probability (S), and

- for adult females, the egg laying rate $(\mathrm{F})$.

It is assumed that each of these parameters $\mathrm{R}, \mathrm{S}$ and $\mathrm{F}$ will depend only on the current hygrothermal conditions RH and T.

In the model we can make a list, or an array, of the number of mites in each batch in each phase, indexed by the percentage development $d\left\{t_{n}\right\}$, where $t_{n}$ is the current time. So the number of mites in a batch in a phase is described as $N\left\{d\left\{t_{n}\right\}\right\}$, where $d\left\{t_{n}\right\}=0 \%$ at the beginning of the phase. To calculate how further developed this batch of mites are in the next time slice $t_{n+1}$, where $t_{n+1}=t_{n}+t_{\text {unit }}$ and $t_{\text {unit }}$ is typically 1 hour, we use the percentage development per hour $R(R H, T)$. So the new percentage development of this batch of mites at time $t_{n+1}$ is:

$d\left\{t_{n+1}\right\}=d\left\{t_{n}\right\}+R(R H, T)$

During this time some of the mites in the batch will die. To calculate how many mites survive into the next time slice we use the survival probability per hour $S(R H, T)$. So the number of mites surviving into the next time slice is given by:

$N\left\{d\left\{t_{n+1}\right\}\right\}=N\left\{d\left\{t_{n}\right\}\right\} \times S(R H, T)$

It should be noted that $N\left\{d\left\{t_{n+1}\right\}\right\}$ is not an integer and can become very much less than 1 if the conditions are bad for an extended period of time. This can be interpreted as the probability of survival from eradication during this time slice. If $N\left\{d\left\{t_{n+1}\right\}\right\}$ is tiny (less than say 0.000001) then it is very unlikely that this batch will survive and it is removed from the list of batches.

The percentage development rate and survival rate are used in every phase of the life cycle and a subscript is now used to indicate which phase a particular parameter represents. For example $N_{\text {egg }}\left\{d_{\text {egg }}\left\{t_{n}\right\}\right\}$ is the number of eggs with percentage development $d_{\text {egg }}\left\{t_{n}\right\}$, at time $t_{n}$.

The adult phase is a special case, as in addition to the development rate and the survival rate, adult female mites may lay eggs. To calculate how many eggs are laid in the next time slice we use the eggs laid per hour $F(R H, T)$. So the number of fresh eggs laid in the next time slice is given by:

$N_{\text {egg }}\left\{d_{\text {egg }}\left\{t_{n+1}\right\}\right\}=N_{\text {female }} \times F(R H, T)$,

where $d_{\text {egg }}\left\{t_{n+1}\right\}=0 \%$, because they are freshly laid, and $N_{\text {female }}=N_{\text {adult }} / 2$ 
It is assumed for the purposes of this model that half the adults are female (Hodgson (1976)) and that all adult females of all ages can produce eggs if the conditions are favourable. The sex ratio of eggs produced is assumed to be $1: 1$, and there are no differences between the sexes, other than that female mites can lay eggs. These simplifying assumptions can be relaxed if necessary.

This process is repeated each time slice with adult female mites replenishing the supply of eggs, as batches of mites progress through the phases, getting ever more developed, as well as ever more depleted in numbers as they die, until they reach a development of $100 \%$. Once a batch of mites has reached a development of $100 \%$, it is moved into the next phase with a percentage development of $0 \%$. At the end of the final adult phase the mites die and are removed from the model completely.

Error! Reference source not found. is a schematic diagram showing the model of a simplified mite life cycle with only three phases, egg, juvenile and adult. Time proceeds down the page for three consecutive time slices. The RH and T are assumed to be constant throughout each time slice. The structure of each phase is depicted as separate histograms across the page with development as the $\mathrm{x}$ axis and number of mites as the y-axis. Within the histogram, batches are represented by thick vertical bars. The height of each bar represents the number of eggs, juveniles or adults in a batch, and the position along the histogram shows its progress. After each time slice, batches are moved along the histograms until they reach the end and are then either moved into the next stage or, for adults, are removed altogether, representing the end of their lifespan. The bars shrink in size at every time slice depending on the survival rates. The female adults lay fresh eggs which form a new batch at the start of the next egg histogram as indicated by the dotted line.

The model naturally introduces a mix or structure into the population. The population of mites at any one moment will consist of eggs, juveniles and adults, all at different stages of development and age. The exact structure will depend on the history of the population and, to get a realistic prediction of the population dynamics over an extended period of time, it is important to keep track of this structure. For example a population experiencing a period of bad conditions leading to a much depleted population will respond very differently to a period of good conditions than a healthy population would.

\section{The POPMITE simulation}

To use the model in a simulation of a population of a real mite species, it is necessary to have values for the percentage development rate (R), the survival rate (S) for each phase in a mite's life cycle and the egg laying rate for adult females $(\mathrm{F})$ for a wide range of RH and T combinations.

Data from a number of different sources has already been published describing the physiological response of the different phases of individual DP mites to a range of constant RH and T combinations. A selection of this data, suitably analysed, has been used to create a rough simulation. The data comes from different experimental groups, which use different experimental methodologies that may not be compatible. It is therefore difficult to extract anything more than an estimate of the physiological response to the hygrothermal conditions. Indeed in analysing the data our primary intention at this time is not to derive accurate relationships, but to provide data to illustrate the model. We therefore have not provided measures of the quality of the fits to the data. The authors of this paper are collecting a fuller and more consistent set of data to be used by the simulation which will potentially give a more precise prediction. The data and a description of an improved simulation will be published at a later date.

From the published data for the model we require the mathematical descriptions or formulae of the parameters:

- $R_{\text {egg }}(R H, T), R_{\text {juvenile }}(R H, T), R_{\text {adult }}(R H, T)$,

- $S_{\text {egg }}(R H, T), S_{\text {juvenile }}(R H, T), S_{\text {adult }}(R H, T)$, and

- $F(R H, T)$.

Egg development rate $R_{\text {egg }}(R H, T)$

No direct measurement of the development rate of eggs $R_{\text {egg }}(R H, T)$ was found in the literature. There is however quite detailed information on the development duration of eggs for a wide range of $\mathrm{RH}$ and 
$\mathrm{T}$ combinations from which the development rate can be calculated. Table 1 shows the development duration in days of DP eggs held at constant RH and T conditions.

For the purposes of the model we make the simplifying assumption that for any given combination of $\mathrm{RH}$ and $\mathrm{T}$ the development rate is constant throughout the egg life stage. We can then extract the percentage development per hour as $R_{\text {egg }}=100 \% / D_{\text {egg }}$, where $D_{\text {egg }}$ is the development duration in hours calculated from the data recorded in days in Table 1 . Figure 2 shows $R_{\text {egg }}$ plotted against temperature.

A linear function of temperature can be used to describe the egg development rate. Below about $50 \%$ $\mathrm{RH}$ no data was found on the development duration and above 50\% RH no obvious correlation was found with RH (i.e. the development rate did not vary significantly for different $\mathrm{RH}$ values above $50 \%$ for fixed values of temperature).

The solid line on Error! Reference source not found. is a fit to the egg development data and gives a rate of $0.91 \%$ development per day per ${ }^{\circ} \mathrm{C}$. In other words, for every $1{ }^{\circ} \mathrm{C}$ increase in temperature the development rate increases by 0.91 of a percent per day. If we assume that we can extrapolate this function to lower temperatures, then development should stop completely below $9^{\circ} \mathrm{C}$.

Equation 4 is the fit to the data and gives the development rate formula for $R_{\text {egg }}(R H, T)$ in $\%$ development per hour, to be used in the model.

$$
\begin{array}{cc}
R_{\text {egg }}(R H, T)=0.91 \times(T-9) / 24 & T>9^{\circ} \mathrm{C} \\
R_{\text {egg }}(R H, T)=0 & T<9^{\circ} \mathrm{C}
\end{array}
$$

The formula for the development duration of eggs will be useful later for the calculation of the juvenile development rate and the egg survival rate. This is given by equation 5 , where $D_{\text {egg }}(R H, T)$ is in hours,

$$
\begin{array}{cc}
D_{\text {egg }}(R H, T)=\frac{24 \times 100}{0.91 \times(T-9)} & T>9^{\circ} \mathrm{C} \\
D_{\text {egg }}(R H, T)=\infty & T<9^{\circ} \mathrm{C}
\end{array}
$$

\section{Juvenile development rate $R_{\text {juvenile }}(R H, T)$}

No direct measurement of the development rate of the juvenile phases of the DP mite was found in the literature. However some information for the total development duration from fresh eggs to adults is available and, by subtracting the egg development duration, the development duration of juveniles can therefore be inferred. Table 2 shows the total development duration for different combinations of $\mathrm{RH}$ and $\mathrm{T}$. The data is from many sources, and is concentrated along the $75 \% \mathrm{RH}$ row and the $25^{\circ} \mathrm{C}$ column. It can be seen that the lower the temperature, the longer the mites take to develop.

As an intermediate step we need to establish a development rate for the combined egg and juvenile life stages. In order to do so we make the simplifying assumption that, for any given combination of RH and $\mathrm{T}$, the development rate is constant throughout the combined egg and juvenile development life stage. Then we can extract an percentage development per hour as $R_{\text {total }}=100 \% / D_{\text {total }}$, where $D_{\text {total }}$ is the development time in hours calculated from the data recorded in days in Table 2. Figure 3 shows $R_{\text {total }}$ plotted against T.

As with eggs, a linear function of the temperature can be used to describe the combined egg and juvenile development rate. Below about $50 \% \mathrm{RH}$ no data was found on the development duration and above 50\% RH no obvious correlation with development rate was found with RH. This may seem surprising given that water balance is important to mites in that above a threshold RH level they extract moisture from the atmosphere and without this moisture the mites eventually die (Arlian 1992). Mites can survive for a short period of time when the RH is below this threshold and can then recover once the RH goes above the threshold (de Boer et al. 1998). In conditions which oscillate above and below 
the threshold the mite development duration will depend on the length of exposure and absolute level of the low RH conditions. However, in constant conditions with RH below the threshold, mites never get the opportunity to recover and therefore die.

The solid line is a fit to the data and gives a rate of $0.33 \%$ total development per day per ${ }^{\circ} \mathrm{C}$. For every $1{ }^{\circ} \mathrm{C}$ increase in temperature the development rate increases by 0.33 of a percent per day. If we assume that we can extrapolate this function to lower temperatures, then the development should stop completely below about $13^{\circ} \mathrm{C}$.

$$
\begin{array}{cc}
R_{\text {total }}(R H, T)=0.33 \times(T-13) / 24 & T>13^{\circ} \mathrm{C} \\
R_{\text {total }}(R H, T)=0 & T<13^{\circ} \mathrm{C}
\end{array}
$$

The formula for overall development time from eggs to adults is given by,

$$
\begin{array}{cc}
D_{\text {total }}(R H, T)=\frac{24 \times 100}{0.33 \times(T-13)} & T>13^{\circ} \mathrm{C} \\
\mathrm{D}_{\text {total }}(R H, T)=\infty & T<13^{\circ} \mathrm{C}
\end{array}
$$

We can now subtract the egg development duration from the total development duration to get the juvenile development duration.

$$
D_{\text {juvenile }}(R H, T)=D_{\text {total }}(R H, T)-D_{\text {egg }}(R H, T)
$$

The juvenile development rate is therefore

$$
R_{\text {juvenile }}(R H, T)=100 \% / D_{\text {juvenile }}(R H, T)
$$

Adult ageing rate $R_{\text {adult }}(R H, T)$

The adult ageing rate is the rate at which both male and female adults progress towards the end of their natural life span. No direct measurements of this have been found. However table 3 gives the longevity in days of DP adults held at constant RH and T conditions.

The very sparse data there is, shows that adult mites have a much shorter life at low RH than at high RH. Figure 4 shows adult longevity as a function of temperature with two fits to the data.

The longevity of adult mites can therefore be modelled with the following equations with an arbitrary split at $60 \% \mathrm{RH}$. More data is needed to give a better representation of the real response of adult longevity to RH and T.

$\begin{array}{ll}D_{\text {adult }}(R H, T)=24 \times(61.42-T \times 1.31) & R H>60 \% \\ D_{\text {adult }}(R H, T)=24 \times(16.44-T \times 0.32) & R H<60 \%\end{array}$

The longevity data can be used to calculate the rate of ageing in $\%$ ageing per hour.

$R_{\text {adult }}(R H, T)=100 \% / D_{\text {adult }}(R H, T)$

Egg survival rate during development $S_{\text {egg }}(R H, T)$

No data for the survival rates of mite eggs during their development phase was found. However there is data on the mortality ( $\left.M_{\text {egg }}\right)$ at the end of the development phase. This is defined as the percentage of mite eggs which die during the period of development and is given by this formula, 


$$
M_{\text {egg }}=\frac{N_{\text {egg }}-N_{\text {juvenile }}}{N_{\text {egg }}} \times 100 \%
$$

Table 4 shows the egg mortality, in percent, during the development period of mite eggs to juveniles.

The mortality is highest at low temperatures whatever the $\mathrm{RH}$ and also at low $\mathrm{RH}$ at high and low temperatures. There is clearly some discrepancy between the different datasets, especially at $25^{\circ} \mathrm{C}$ and $75 \%$ and $80 \% \mathrm{RH}$. For $\mathrm{RH}$ below an arbitrary cut-off, which by coincidence is also $60 \%$, a simple quadratic of the temperature is used,

$M_{\text {egg }}(R H, T)=195.78-14.35 T+0.32 T^{2} \quad R H<60 \%$

At RHs above $60 \%$ a more complicated exponential of the temperature is used with a simple linear formula for the $\mathrm{RH}$,

$M_{\text {egg }}(R H, T)=31.20-0.19 R H+2754.05 e^{-0.37 T} \quad R H>60 \%$

Figure 5, Figure 6 and Figure 7 show the fits to the data.

The mortality is equal to a hundred percent minus the survivability,

$M_{\text {egg }}(R H, T)=100 \%-s_{\text {egg }}$

The survivability is the product of all the hourly survival rates during the development duration, and is therefore given by

$$
S_{\text {egg }}=S_{\text {egg }} D_{\text {egg }}(R H, T) / t_{\text {unit }}
$$

This leads to an hourly survival rate, which can be used in the model.

$$
S_{\text {egg }}(R H, T)=\left(1-\frac{M_{\text {egg }}(R H, T)}{100 \%}\right)^{t_{u n i t} / D_{\text {egg }}(R H, T)}
$$

It is important to note that the hourly survival rate depends on the development duration as well as the mortality of eggs.

Survival rate during the juvenile phases $S_{\text {juvenile }}(R H, T)$

No data for the survival rates of juvenile mites during their development phase was found. To calculate the juvenile hourly survival rate, the total mortality during the overall mite development from egg to adult is used. It is defined, in a similar way to the mortality during the egg development period, as the percentage of mites which die during the overall period of development and is given by this formula:

$M_{\text {total }}=\frac{N_{\text {egg }}-N_{\text {adult }}}{N_{\text {egg }}} \times 100 \%$

Table 5 shows the total mortality, in percent, during the development of mites from fresh eggs to adults.

The data is concentrated along the $75 \% \mathrm{RH}$ row and the $25^{\circ} \mathrm{C}$ column. The mortality increases at low and high $\mathrm{RH}$, and also at low and high temperatures. The minimum mortality is at $80 \% \mathrm{RH}$ and $25^{\circ} \mathrm{C}$. Two independent quadratic curves are used to fit the RH and the temperature data separately and are then combined together assuming there are no cross correlations. 
$M_{\text {total }}(R H, T)=803.59-15.97 R H+0.11 R H^{2}+14.14 T+0.27 T^{2}$

Error! Reference source not found. and Error! Reference source not found. shows the data and the fits.

The probability of mortality during the complete development period is equal to the product of the probability of mortality during the egg development phase and the juvenile phase.

$\frac{M_{\text {total }}(R H, T)}{100 \%}=\frac{M_{\text {egg }}(R H, T)}{100 \%} \times \frac{M_{\text {juvenile }}(R H, T)}{100 \%}$

Using the same logic from the previous section on the survival rate during the egg development phase, the hourly survival rate of juveniles is given by:

$$
S_{\text {juvenile }}(R H, T)=\left(1-\frac{M_{\text {juvenile }}(R H, T)}{100 \%}\right)^{t}{ }^{u n i t} / D_{\text {juvenile }}(R H, T)
$$

Substituting equation 20 into equation 21 gives

$$
S_{\text {juvenile }}(R H, T)=\left(1-\frac{M_{\text {total }}(R H, T)}{M_{\text {egg }}(R H, T)}\right)^{t} \text { unit }^{/ D_{\text {juvenile }}(R H, T)}
$$

\section{Survival rate during the adult phase $S_{\text {adult }}(R H, T)$}

Since no direct or indirect measurements of the survival rates or mortality for adults have been published, we have assumed that the mortality of adults is the same as the mortality of juveniles.

$M_{\text {adult }}=M_{\text {juvenile }}=\frac{M_{\text {total }}}{M_{\text {egg }}} \times 100 \%$

This leads to the rate of adult mites surviving per hour as:

$$
S_{\text {adult }}(R H, T)=\left(1-\frac{M_{\text {adult }}(R H, T)}{100 \%}\right)^{t} \text { unit } / D_{\text {adult }}(R H, T)
$$

Substituting equation 23 into equation 24 gives:

$$
S_{\text {adult }}(R H, T)=\left(1-\frac{M_{\text {total }}(R H, T)}{M_{\text {egg }}(R H, T)}\right)^{t_{\text {unit }} / D_{\text {adult }}(R H, T)}
$$

\section{Adult female egg laying rate $F_{\text {adult }}(R H, T)$}

The fecundity or total mean number of eggs produced by a female mite during her adult life is given in Table 6 in number of eggs.

A cubic formula for both $\mathrm{RH}$ and temperature is used to describe the data,

$$
f=336.71-65.08 R H+1.16 R H^{2}-0.0064 R H^{3}+89.02 T-3.04 T^{2}+0.032 T^{3}
$$

Error! Reference source not found. and Error! Reference source not found. show the data and the fits. 
The simplifying assumption has been made that female adults lay eggs at a constant rate throughout their adult lifetime. Therefore the probability that they will lay eggs in any one time slice is given by:

$F(R H, T)=f \times t_{\text {unit }} / D_{\text {adult }}(R H, T)$

\section{Using the POPMITE Simulation}

The POPMITE simulation program has been written in PERL (www.perl.com). POPMITE can read the hygrothermal conditions, together with a description of the initial structure of the mite population, and predict the population dynamics.

To illustrate how the model functions, POPMITE has been used to predict the population dynamics of 100 freshly laid eggs (no juveniles or adults at the start) in an arbitrarily chosen constant climate of $75 \% \mathrm{RH}$ and $35^{\circ} \mathrm{C}$ for 30 days. Error! Reference source not found. shows the results.

The plot shows the number of mites as a function of time. Initially there are 100 eggs at the beginning of the first day. Over the next 4 days (the development period at $35^{\circ} \mathrm{C}$ ) the number of eggs has decreased to roughly $80 \%$ (the survival probability). At this point all the eggs turn into juveniles and the number of eggs drops to zero. After approximately 10 further days the number of juveniles has decreased to $60 \%$ approximately to leave about 45 juveniles. At this point the juveniles turn into adults and the number of juveniles drops to zero. Immediately the adults start to lay new eggs. Fresh batches of new eggs are then laid every time slice, depending on the number of adults. The number of adults gradually decreases, according to the survivability rate. However after 4 further days the first of the new eggs to be laid start to hatch into juveniles, and the number of juveniles starts to increase. The number of eggs in the population is then equal to the number of eggs being laid minus the number of eggs dying, minus the number of eggs changing into juveniles, and so the egg population starts to decrease. After a further 10 days the juveniles start to turn into adults, and there is consequently a sharp drop in the number of juveniles, a sharp rise in the number of adults and also a sharp rise in the number of eggs. At 29 days the number of adults drops sharply before the upward trend resumes. These are the adults from the original batch of eggs dying.

If this simulation is left to run for any length of time the population of mites will quickly become enormous, which is to be expected for these relatively favourable conditions, with unlimited food supplies.

Preliminary validation by comparison of POPMITE predictions with measurements of mite
population growth.

The DP mite population growth and decline, after a 21 day period, under a range of constant RH and temperature conditions, have been measured as reported by Crowther et al. (2006). A population growth multiplication factor was calculated for each $\mathrm{RH}$ and temperature combination by comparing the final population of juveniles and adults with the initial population of juveniles and adults. The population of eggs was not measured but as the initial populations were mature and well mixed it was assumed that there were a similar number of eggs in each sample. No measurement, other than the combined total number of juveniles and adults, was made of the initial population structure.

POPMITE can be used to predict the measurements of the population growth factor. With no other information on the starting population structure, we assume a population structure of 1:1:1 of eggs, juveniles and adults with a spread over all ages. The predictions and data with statistical error bars from Crowther et al (2006) are shown as a function of RH in figures 13, 14, 15, 16 and 17 for fixed temperatures of $15^{\circ} \mathrm{C}, 20^{\circ} \mathrm{C}, 25^{\circ} \mathrm{C}, 30^{\circ} \mathrm{C}$ and $35^{\circ} \mathrm{C}$ respectively. The discontinuity at $60 \% \mathrm{RH}$ in the POPMITE predictions in figures 13 to 17 are due to the use of the arbitrary step change at $60 \%$, as explained earlier, in equation 10 to describe adult longevity and equations 13 and 14 to describe egg mortality.

The POPMITE model under-predicts the growth factor at high $\mathrm{RH}$ when the temperature is $30^{\circ} \mathrm{C}$, but otherwise the predictions and measurements show a good agreement with each other over the whole $\mathrm{RH}$ and $\mathrm{T}$ range. 
A similar experiment as described by Crowther et al with more detailed measurements of the initial and final population structures should be able to provide a more comprehensive validation of POPMITE under constant conditions. However the very good agreement with the present data gives confidence in POPMITE and allows for a preliminary validation.

\section{Predicting mite population growth at a range of constant conditions}

The POPMITE simulation program can now be used to predict mite population growth or decline for a wide range of constant $\mathrm{RH}$ and $\mathrm{T}$ combinations. Figure 18 shows the predicted growth of a population consisting of 100 freshly laid eggs after 30 days. The thick contour represents the RH and T combinations where the complete population (eggs, juveniles and adults) is numerically equal to the starting population. Figure 18 show a central 'island' of growth with a maximum growth factor of 11.476 (538.8 Eggs, 553.9 Juveniles and 54.9 Adults) at $29^{\circ} \mathrm{C}$ and $76 \% \mathrm{RH}$. Outside this island the populations are in decline, with a higher decline at higher temperatures.

The discontinuity at $60 \%$ RH in Figure 18 is again due to the use of the arbitrary step change at $60 \%$ in equation 10 to describe adult longevity and equations 13 and 14 to describe egg mortality.

Figure 18 shows the population growth for only 30 days, which means that for populations at low temperatures the mites have not yet completed a full life cycle. At temperatures below $13^{\circ} \mathrm{C}$ eggs will not have had time to hatch into juveniles, and below about $24^{\circ} \mathrm{C}$ juveniles will not have had time to turn into adults. The lower bound of the 'island' of growth at $24^{\circ} \mathrm{C}$ as shown in Figure 18 is due to mites not reaching maturity and therefore being unable to produce eggs to increase the population.

Figure 19 shows the predicted growth of a population consisting of 100 freshly laid eggs after 60 days. The maximum growth factor of 365.293 (20,002.9 Eggs, 13,062.7 Juveniles and 3,463.7 Adults) is now at $31^{\circ} \mathrm{C}$ and $76 \% \mathrm{RH}$, which is at a slightly higher temperature than the predicted maximum of $29^{\circ} \mathrm{C}$ for the 30 day simulations. It is also massively increased. Mites held in these conditions are unlikely to reach such numbers unless there is an unlimited amount of food and space available to them. Wilkinson et al. (2002) have shown that 1 gram of food is enough for a population of about 12,000 mites (juveniles and adults) to develop after 18 weeks from only 2 mating pairs held at $25^{\circ} \mathrm{C}$ and $75 \% \mathrm{RH}$. The population then gradually declined as the food was consumed. A limit on the population growth based on the available food can be incorporated into POPMITE if needed. This will be the subject of a future paper by the authors.

The area over which the population is either stable or growing is now much larger. However the lower bound of this growth 'island' is again due to the fact that below $18^{\circ} \mathrm{C}$ juveniles will not have been able to turn into adults.

The total mortality as described by equation 19 and shown in Figure 8 has a minimum at $26^{\circ} \mathrm{C}$ and the fecundity as described by equation 26 and Figure 11 has a maximum at $23^{\circ} \mathrm{C}$. This would suggest that the maximum growth factor should be found at much lower temperatures than the $29^{\circ} \mathrm{C}$ for 30 days and $31^{\circ} \mathrm{C}$ for 60 days. The reason for this apparent discrepancy is that even though the conditions are less favourable, the development rate is very much increased at higher temperatures. The mites are therefore able to replenish their numbers at a faster rate than mites held at lower temperatures.

It is interesting to note that the models based on the constant growth multiplication factor (Crowther et al. 2006) would have predicted a different growth factor after 60 days given the growth after 30 days. Assuming that the growth was constant over the first 30 days then the growth multiplication factor per

day would have been $11.476^{(1 / 30)}=1.085$. In other words if there where 100 mites then at the end of first day there will be 108.5 mites and at the end second day will be 117.2 mites and so on. This model then predicts a population growth of only $1.085^{60}=131.699$ after 60 days compared to the POPMITE prediction of 365.293. This illustrates the different results that can be obtained when population structure is taken into account.

\section{Simulation using changing hygrothermal conditions}

Once it has been further validated, the model can be used to predict the population dynamics of mites held in constant hygrothermal conditions. Unfortunately the hygrothermal conditions of the typical habitats of mites, such as a mattress, can vary dramatically. Ridley et al. (2006) have recorded the 
micro-climatic conditions found throughout the beds of a number of people over a period of a few days. These measurements show that when the bed is empty the mattress is in climatic equilibrium with the bedroom. However once the bed is occupied there is a dramatic increase in the absolute humidity and temperature in the mattress immediately under the body. The temperature increase is usually so high that the corresponding RH drops. Even though the absolute humidity in the bed has increased due to the presence of a sweating, moisture breathing sleeping person, the excess vapour is not enough to increase the relative humidity, since the temperature has risen by a disproportionately large amount at the same time, thus resulting in a drop in relative humidity. For a discussion on this point see Pretlove et al. (2005)

POPMITE can accept continually changing conditions as input, although the quality of the prediction is likely to be degraded the greater the transient nature of the hygrothermal conditions. The reason for this is that at present the model assumes that the survival rates for each phase are constant; in other words the probability of surviving in one time slice does not depend on how long that batch of mites has been exposed to the current environment.

De Boer et al. $(1997,1998)$ and Pike et al. (2005) have shown that DP populations held in unfavourable conditions of low RH, but given brief periods of favourable high RH conditions every day, are able to survive and even grow. Mite populations held continuously in harsh conditions decline and eventually die out. This suggests that individual mites have a survival probability which depends on how long they are held in harsh conditions.

Arlian and Wharton (1974), Arlian (1975, 1992), Wharton (1978), Arlian and Veselica (1979, 1981a,b) and de Boer (2000) have investigated the water balance of mites (DP and Dermatophagoides farinae) and have developed equations which describe the water content of a mite under different hygrothermal conditions. In low RH conditions mites initially lose moisture very quickly, but after a short period of time are able to reduce the water loss drastically, enabling them to survive for an extended period of time. In high RH conditions, mites are able to recover any lost moisture very quickly and to maintain it at high levels to allow them to function and reproduce.

An improvement to the POPMITE model is therefore being developed which will include parameters to track the water contents of mites and therefore reproduce the correct response to conditions fluctuating between high and low RH. Until this is available a minimum survival rate is applied to all batches to allow at least some mites to survive unfavourable conditions. However the resultant predictions are unlikely to be accurate in very transient conditions.

\section{Conclusions}

A generalised model of the life cycle of a house dust mite is presented. Previously published data on the physiological effects of exposure of the DP mite to constant relative humidity and temperature combinations is used to construct a model and computer simulation called POPMITE. For a given starting population structure and climate history, POPMITE is able to predict the most likely population dynamics for the house dust mite DP.

Preliminary validation by comparisons of the POPMITE predictions with measurements of population growth at constant hygrothermal conditions shows good agreement.

Contour plots showing the predicted growth of a population consisting of 100 freshly laid eggs after 30 days and 60 days in a range of RH and T combinations show that temperature plays an important role in controlling the growth and decline of populations.

POPMITE produces very different predictions from models based on the assumption of a constant growth multiplication factor, which are the basis of the models of Cunningham and Crowther. These models are simple and easy to use and can gave a broad indication of the population growth, but they will never be able to give as accurate a prediction as POPMITE, since the population structure and therefore the population growth multiplication factor changes all the time, even under constant conditions.

The current version of POPMITE, when fully validated, will give good predictions of house dust mite population dynamics where conditions are constant or changing slowly, but will tend to give degraded 
predictions once conditions start to fluctuate. This is still a significant improvement on the models of Cunningham and Crowther, and POPMITE can already be used as part of a study to test scenarios for changing building design or occupant behaviour to reduce mite populations in beds.

A study to provide a precise and comprehensive dataset of the physiological response of DP to a wide range of both constant and varying environmental conditions and diets is under way. This dataset is required to calibrate the parameters needed to track the moisture content of mites for a more accurate version of the POPMITE simulation that will be able to cope fully with varying hygrothermal conditions.

\section{Acknowledgments}

This research project has been funded by the UK Engineering and Physical Sciences Research Council. Grant number GR/S70661/01. 


\section{References}

Andersen, A (1988) Population growth and developmental stages of the house dust mite, Dermatophagoides pteronyssinus (Acari: Pyroglyphidae). J. Med Entomol. 25: 370-373

Arlian LG (1975) Dehydration and survival of the European house dust mite, Dermatophagoides pteronyssinus. Journal of Medical Entomology, 12/4: 437-442

Arlian LG (1992) Water balance and humidity requirements of house dust mites. Experimental \& Applied Acarology, 16: 15-35

Arlian LG, Rapp CM and Ahmed SG (1990) Development of Dermatophagoides pteronyssinus (Acari: Pyroglyphidae). Journal of Medical Entomology, 27/6: 1035-1040

Arlian LG and Veselica MM (1979) Water balance in insects and mites. Comp Biochem Physiol, 64A: 191-200

Arlian LG and Veselica MM (1981a) Effect of temperature on the equilibrium body water mass in the mite Dermatophagoides farinae. Physiology Zoology, 54/4: 393-399

Arlian LG and Veselica MM (1981b) Re-evaluation of the humidity requirements of the house dust mite Dermatophagoides farinae (Acari: Pyroglyphidae). Journal of Medical Entomology, 18/4: 351-352

Arlian LG and Wharton GW (1974) Kinetics of active and passive components of water exchange between the air and a mite, Dermatophagoides farinae. Journal of Insect Physiology, 20: 10631077

Blythe, M.E (1976) Some aspects of the ecological study of the house dust mite. Brit. J. Dis. Chest 70: 3-31.

Boer R de (2000) Rates of water vapour uptake and loss by the house dust mite, Dermatophagoides pteronyssinus (Acari: Pyroglyphidae). Proceedings of Experimental \& Applied Entomology, 11: $73-76$

Boer R de and Kuller K (1997) Mattresses as a winter refuge for house-dust mite populations. Allergy, 52: 299-305

Boer R de, Kuller K and Kahl O (1998) Water balance of Dermatophagoides pteronyssinus (Acari: Pyroglyphidae) maintained by brief daily spells of elevated air humidity. Journal of Medical Entomology, 35/6: 905-910

Bronswijk JE van (1981) House Dust Biology for Allergists, Acarologists and Mycologists. NIB Publishers, The Netherlands

Case T J (2000) An Illustrated Guide to Theoretical Ecology. Oxford Univ Press. New York.

Colloff, M. J (1987a) Effects of temperature and relative humidity on development times and mortality of eggs from laboratory and wild populations of the European house dust mite Dermatophagoides pteronyssinus (Acari: Pyroglyphidae). Experimental and Applied Acarology 3 : 279-289.

Colloff, M. J (1987b) Differences in development time, mortality and water loss between eggs from laboratory and wild populations of Dermatophagoides pteronyssinus. Experimental and Applied Acarology 3 : 191-200.

Colloff M (1998) Taxonomy and identification of dust mites. Allergy 53 Supplement 48 : 7-12

Crowther D, Wilkinson T, Biddulph P, Oreszczyn T, Pretlove S and Ridley I (2006). A simple model for predicting the effect of hygrothermal conditions on populations of house dust mite Dermatophagoides pteronyssinus (Acari: Pyroglyphidae). Experimental and Applied Acarology, 79(2): $127-148$

Cunningham MJ (2000) A proposed experimental programme towards control of dust mites by microclimate modification, in Mites, Asthma and Domestic Design III (Eds: Siebers R, Cunningham M, Fitzharris P and Crane J). Wellington Asthma Research Group, Department of Medicine, Otago University, 2000

Dobson R.M (1979) Some effects of microclimate on the longevity and development of Dermatophagoides pteronyssinus (Trouessart). Acarologia 21: 482-486.

Ford AW, Rawle FC, Lind P, Spieksma FTM, Lowenstein H and Platts-Mills TAE (1985) Standardization of Dermatophagoides pteronyssinus: Assessment of potency and allergen content in ten coded extracts. International Archives of Allergy and Applied Immunology 76: 58-67.

Gamal-Eddin FM, Abou-Sinna FM, Tayel SE, Aboul-Atta AM, Seif AM, Gaafar SM (1983a). Duration of the developmental stages of house dust mites Dermatophagoides farinae and DP under controlled temperatures and relative humidities to pave the way in from of the workers in the field of house dust mite bronchial asthma. 1. Pre-imaginal period. Journal of the Egyptian Society of Parasitology 13 : 319-334. 
Gamal-Eddin FM, Shehata KK, Tayel SE, Abou-Sinna FM, Aboul-Atta AM, Seif AI, Imam MH, Hafez AH (1983b). Duration and the development stages of house-dust mites Dermatophagoides farinae and D. pteronyssinus under controlled conditions to pave the way in front of the workers in the field of house-dust mite asthmatic bronchitis. 2. Oviposition period, fecundity and oval duration. Journal of the Egyptian Society of Parasitology, 13: 557-581

Gamal-Eddin FM, Shehata KK, Abou-Sinn FM, Tayel SE, Aboul-Atta AM, El-Ahmedaawy BA, Fayed MA, Hafez AH and Imam MH (1983c) Duration of the developmental stages of house dust mites DF and DP under controlled conditions to pave the way in from of the workers in the field of house dust mite asthmatic bronchitis 3. Larval Duration. Journal of the Egyptian Society of Parasitology $13: 583-595$

Hart, BJ. and Fain, A (1988) Morphological and biological studies of medically important house-dust mites. Acarologia 29: 285-295.

Ho, TM. and Nadchatram, M (1984) Life cycle and longevity of Dermatophagoides pteronyssinus (Trouessart) (Acarina: Astigmata: Pyroglyphidae) in a tropical laboratory. Trop. Biomed 1: 159162.

Hodgson, R.K (1976) Sex ratio and sex determination in the American house dust mite, Dermatophagoides farinae. Annals Ent. Soc America, 69: 1085-6.

Nisbet, RM. and Gurney, WSC. (1982) Modelling Fluctuating Populations. John Wiley and Sons, Chichester.

Leslie, PH. (1945) On the use of matrices in certain population mathematics. Biometrika, 35: 183-212.

Pretlove S, Oreszczyn T, Ridley I, Wilkinson T and Crowther D (2005) A steady state model for predicting hygrothermal conditions in beds in relation to house dust mite requirements. Building Services Engineering Research \& Technology, 26/4: 301-314

Pike A, Cunningham M and Lester P (2005) Development of Dermatophagoides pteronyssinus (Acari: Pyroglyphidae) at constant and simultaneously fluctuating temperature and humidity conditions. Journal of Medical Entomology, 42/3: 266-269

Ridley I, Biddulph P, Oreszczyn T, Pretlove S, Crowther D, Wilkinson T, Ucci M and Hart B (2006) A model to predict the hygrothermal conditions experienced by house dust mites within beds. Submitted to Indoor Air.

Spieksma, F. Th M (1967) The House Dust Mite Dermatophagoides pteronyssinus (Trouessart, 1897). $\mathrm{PhD}$ Thesis, Univ. of Leiden, $65 \mathrm{pp}$.

U.S. Department of Energy (US-DOE) (2004) EnergyPlus Energy Simulation Software. http://www.eere.energy.gov/buildings/energyplus

Voorhorst R, Spieksma F and Varekamp H (1969) House Dust Atopy and the House Dust Mite, Dermatophagoides pteronyssinus (Trouessart, 1897). Stafleu's Scientific Publishing Company, Leiden

Wharton G (1978) Uptake of water vapour by mites and mechanisms utilized by the Acaridei. In Comparative Physiology: Water, Ions and Fluid Mechanics (Eds: Schmidt-Nielsen K, Bolis L and Maddrell S). Cambridge University Press, Cambridge.

Wilkinson T, Horwood J, Cox P, Crowther D, Ridley I, Pretlove S and Oreszczyn T (2002) Factors affecting the carrying capacity $(\mathrm{K})$ of a mattress for the house dust mite Dermatophagoides pteronyssinus (Acari: Pyroglyphidae) $11^{\text {th }}$ International Congress of Acarology. Universidad Nacional Autonoma de Mexico, Merida, Yucatan, Mexico, $8^{\text {th }}-13^{\text {th }}$ September 2002 


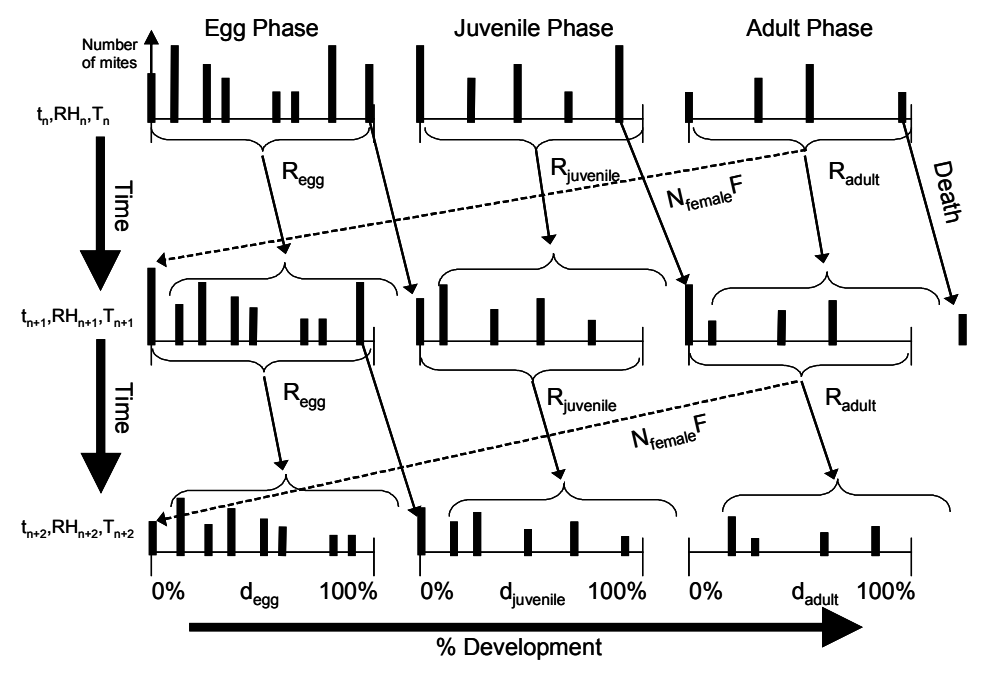

Figure $1 \quad$ Schematic diagram of a simplified mite life cycle



Figure 2 Dermatophagoides Pteronyssinus (Acari: Pyroglyphidae) mite egg development rate as a function of temperature 




Figure 3 Dermatophagoides Pteronyssinus (Acari: Pyroglyphidae) mite total development rate (from egg to adult) as a function of temperature

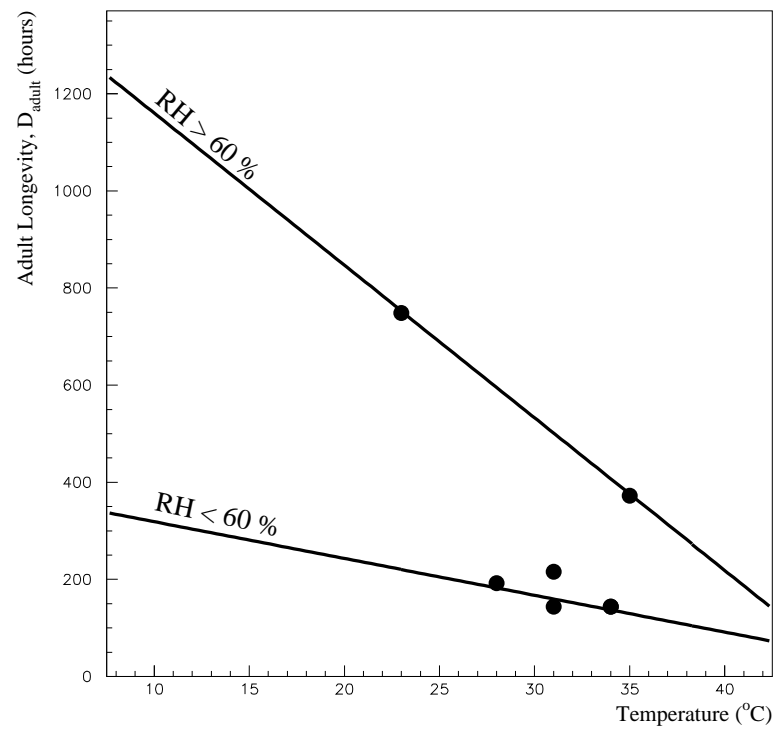

Figure 4 Dermatophagoides Pteronyssinus (Acari: Pyroglyphidae) mite adult longevity as a function of temperature 


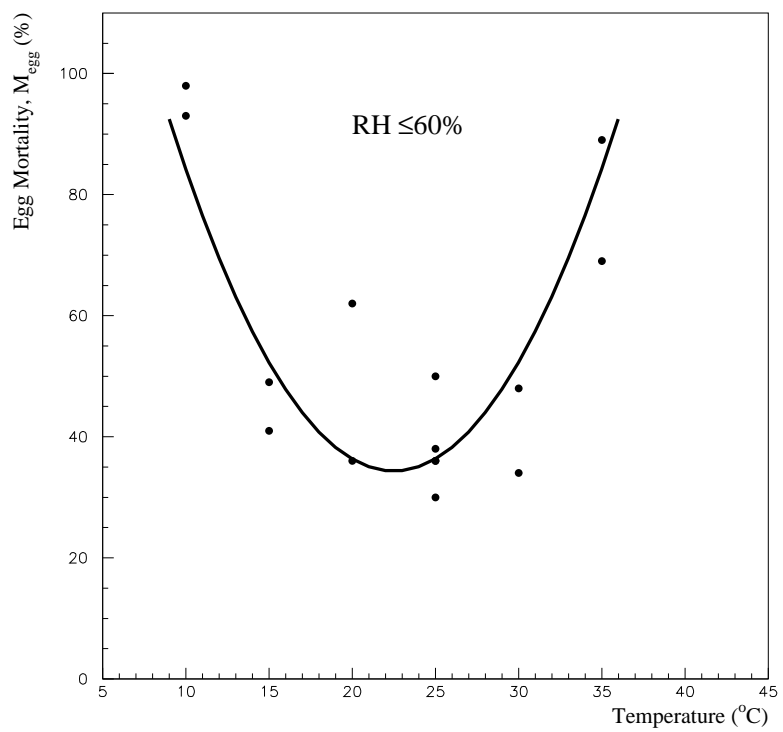

Figure 5 Dermatophagoides Pteronyssinus (Acari: Pyroglyphidae) mite egg mortality as a function of temperature for relative humidity values less than $60 \%$

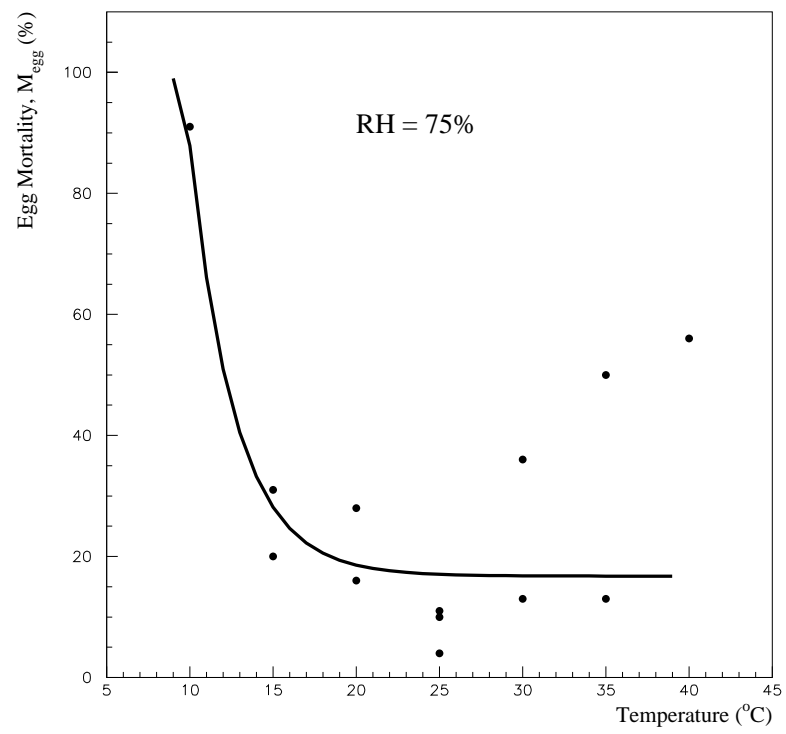

Figure 6 Dermatophagoides Pteronyssinus (Acari: Pyroglyphidae) mite egg mortality as a function of temperature at a fixed relative humidity of $75 \%$ 


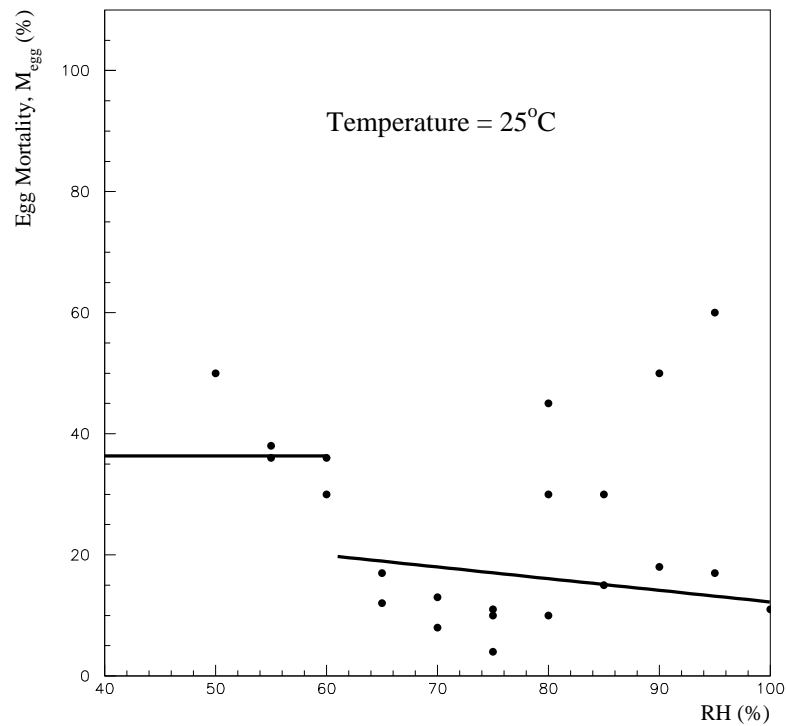

Figure 7 Dermatophagoides Pteronyssinus (Acari: Pyroglyphidae) mite egg mortality as a function of relative humidity at a fixed temperature of $25^{\circ} \mathrm{C}$

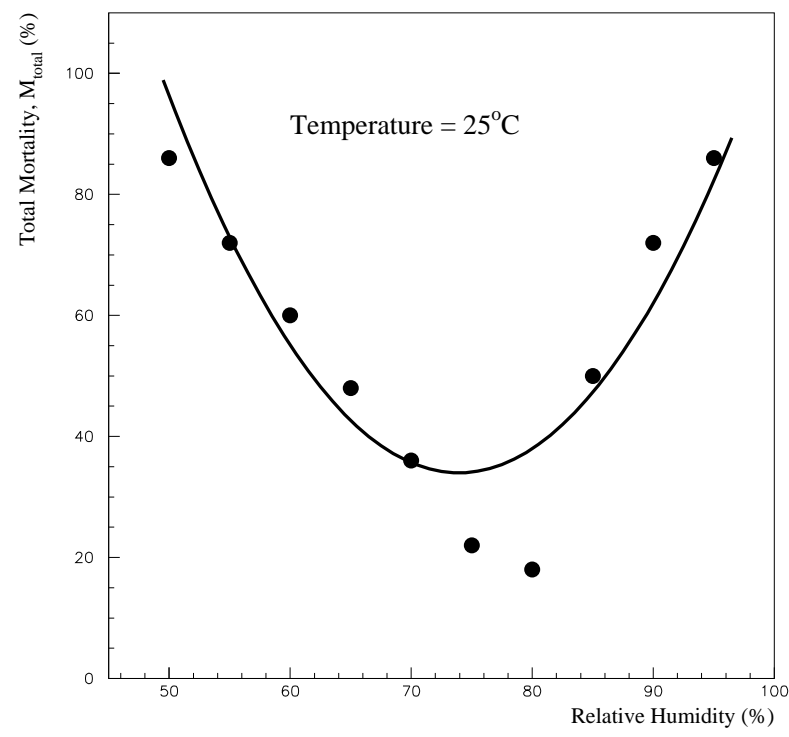

Figure 8 Dermatophagoides Pteronyssinus (Acari: Pyroglyphidae) mite total mortality, from egg to adult, as a function of relative humidity for a fixed temperature of $25^{\circ} \mathrm{C}$ 


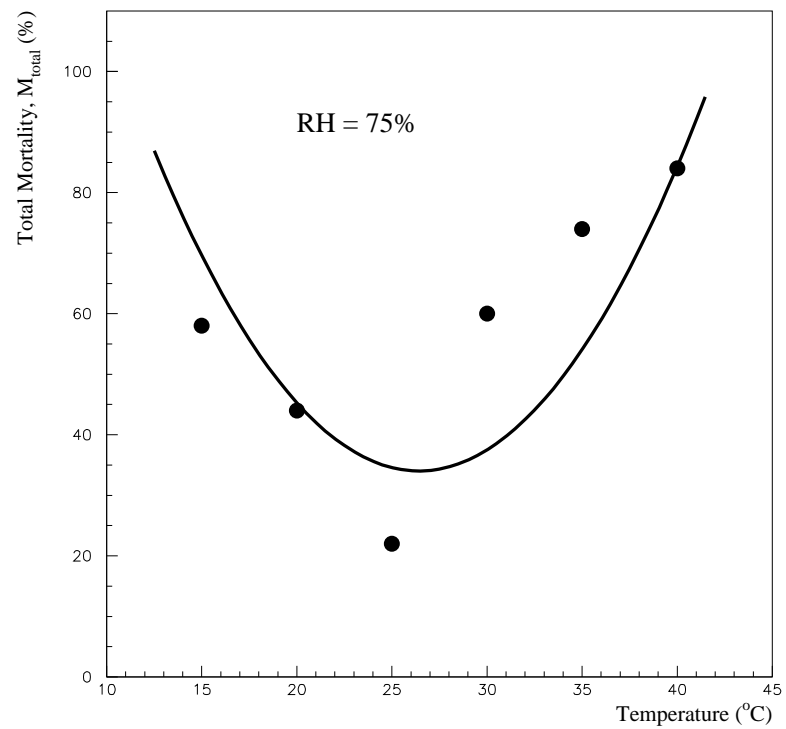

Figure 9 Dermatophagoides Pteronyssinus (Acari: Pyroglyphidae) mite total mortality, from egg to adult, as a function of Temperature for a fixed relative humidity of $75 \%$

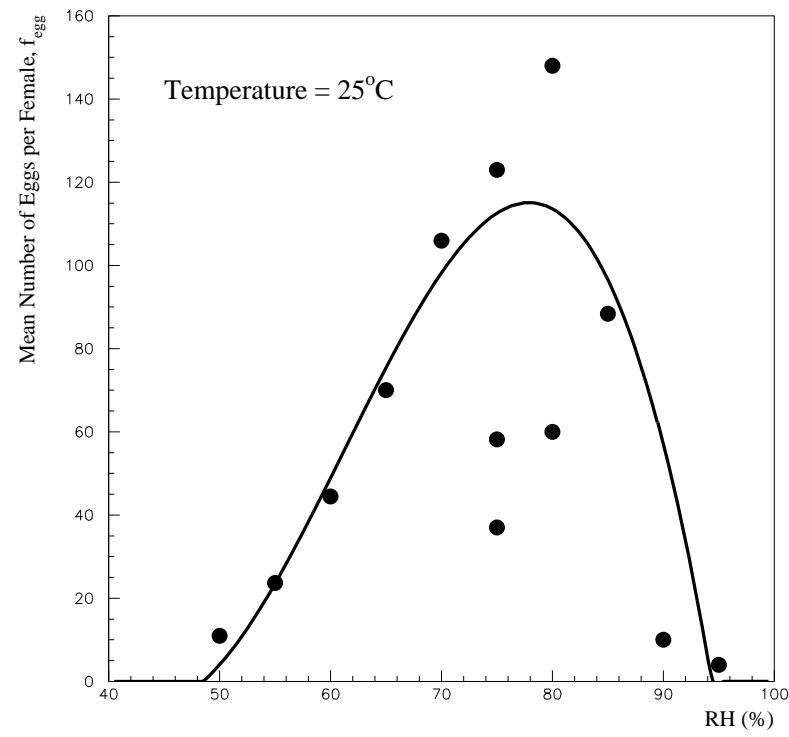

Figure 10 Dermatophagoides Pteronyssinus (Acari: Pyroglyphidae) mite mean number of eggs per female during adult life as a function of relative humidity at a fixed temperature of $25^{\circ} \mathrm{C}$ 


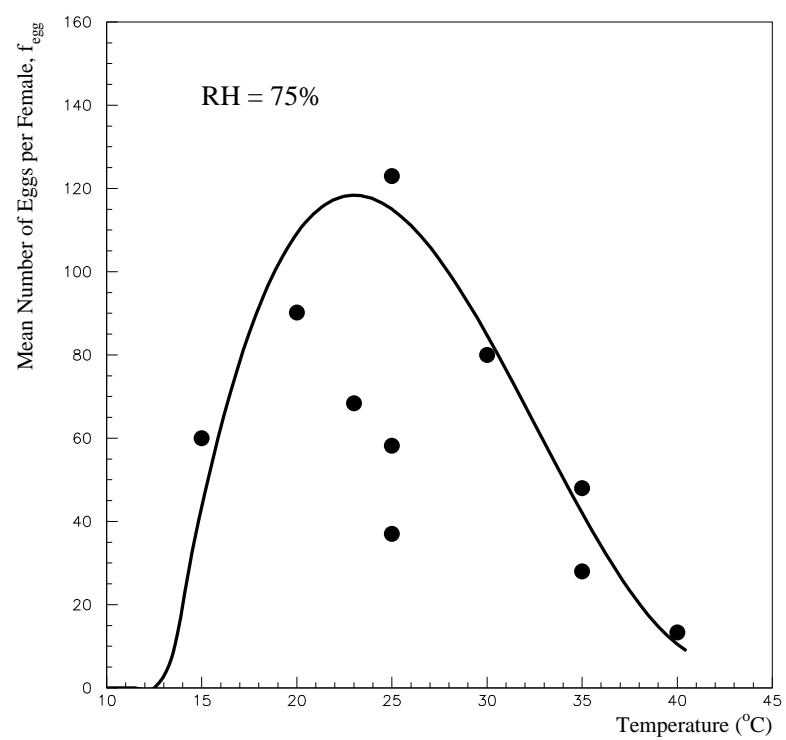

Figure 11 Dermatophagoides Pteronyssinus (Acari: Pyroglyphidae) mite mean number of eggs per female during adult life as a function of Temperature at a fixed relative humidity of $75 \%$

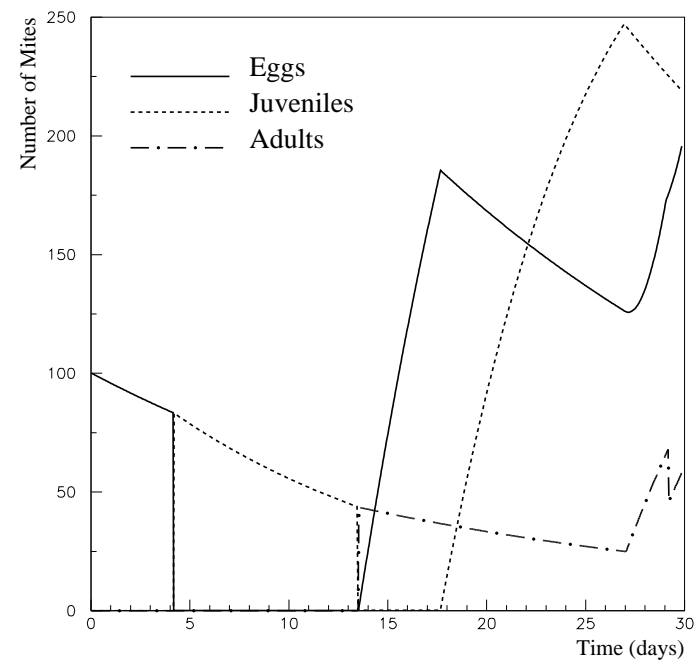

Figure 12 Prediction of the population dynamics of a batch of 100 freshly laid eggs held at a constant temperature of $35^{\circ} \mathrm{C}$ and a constant relative humidity of $75 \%$. The total number of eggs in all batches is plotted as a solid line, the total number of juveniles as a dashed line and the total number of adults as a dash-dotted line 


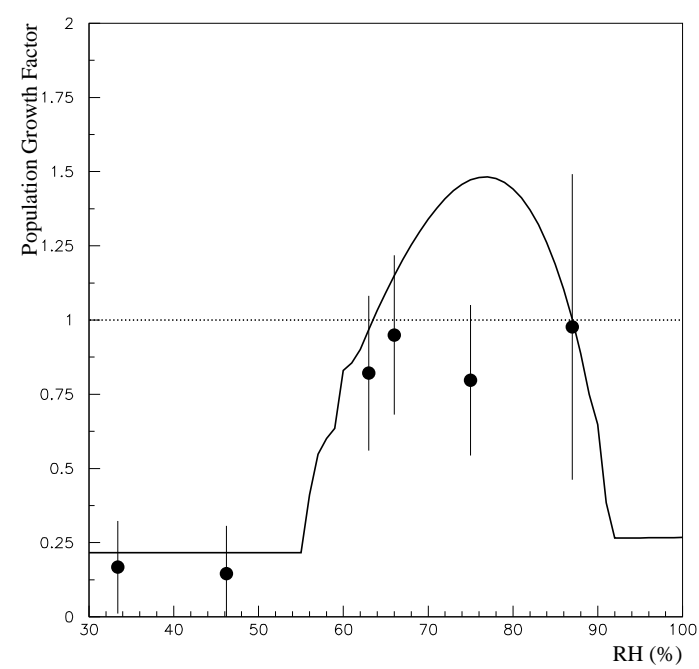

Figure 13 Comparison of the POPMITE prediction (solid line) with data from Crowther et al (2006) of the population growth multiplication factor of Dermatophagoides Pteronyssinus (Acari: Pyroglyphidae) for a range of $\mathrm{RH}$ values at a fixed temperature of $15^{\circ} \mathrm{C}$.

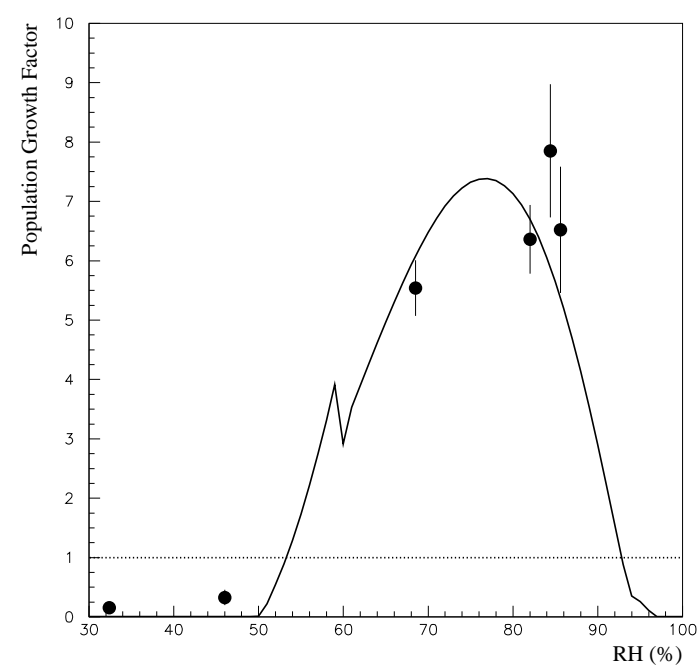

Figure 14 Comparison of the POPMITE prediction (solid line) with data from Crowther et al (2006) of the population growth multiplication factor of Dermatophagoides Pteronyssinus (Acari: Pyroglyphidae)for a range of $\mathrm{RH}$ values at a fixed temperature of $20^{\circ} \mathrm{C}$. 


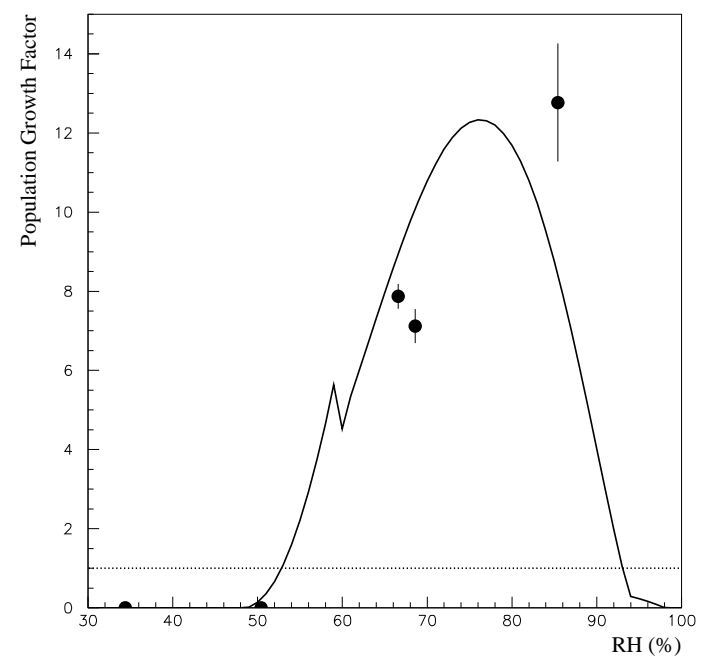

Figure 15 Comparison of the POPMITE prediction (solid line) with data from Crowther et al (2006) of the population growth multiplication factor of Dermatophagoides

Pteronyssinus (Acari: Pyroglyphidae)for a range of $\mathrm{RH}$ values at a fixed temperature of $25^{\circ} \mathrm{C}$.

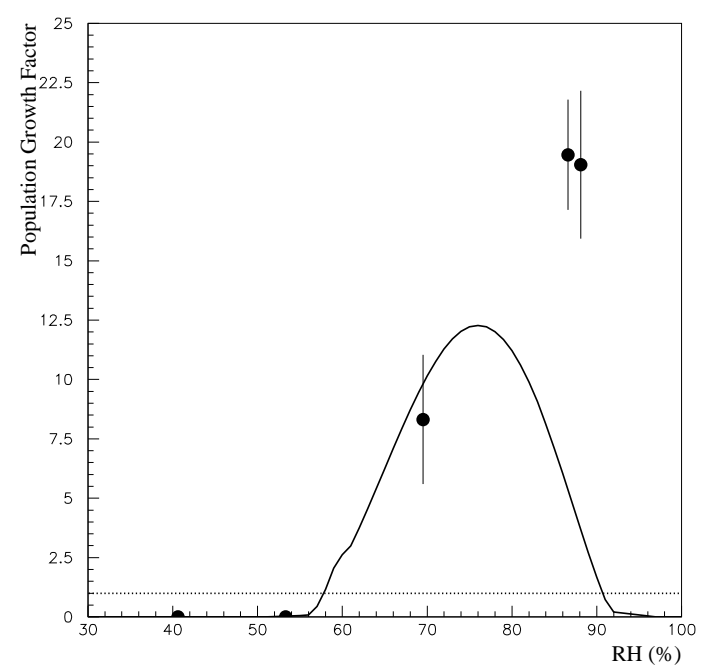

Figure 16 Comparison of the POPMITE prediction (solid line) with data from Crowther et al (2006) of the population growth multiplication factor of Dermatophagoides Pteronyssinus (Acari: Pyroglyphidae)for a range of $\mathrm{RH}$ values at a fixed temperature of $30^{\circ} \mathrm{C}$. 


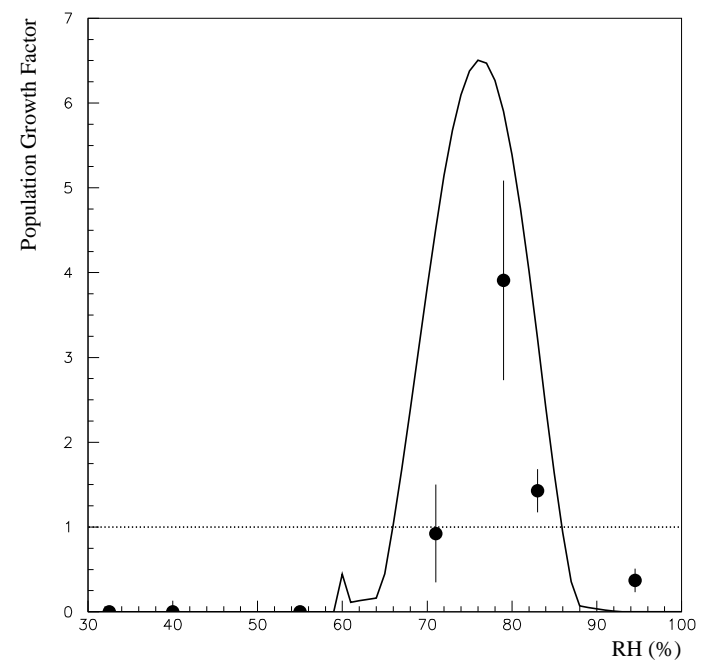

Figure 17 Comparison of the POPMITE prediction (solid line) with data from Crowther et al (2006) of the population growth multiplication factor of Dermatophagoides

Pteronyssinus (Acari: Pyroglyphidae)for a range of $\mathrm{RH}$ values at a fixed temperature of $35^{\circ} \mathrm{C}$.

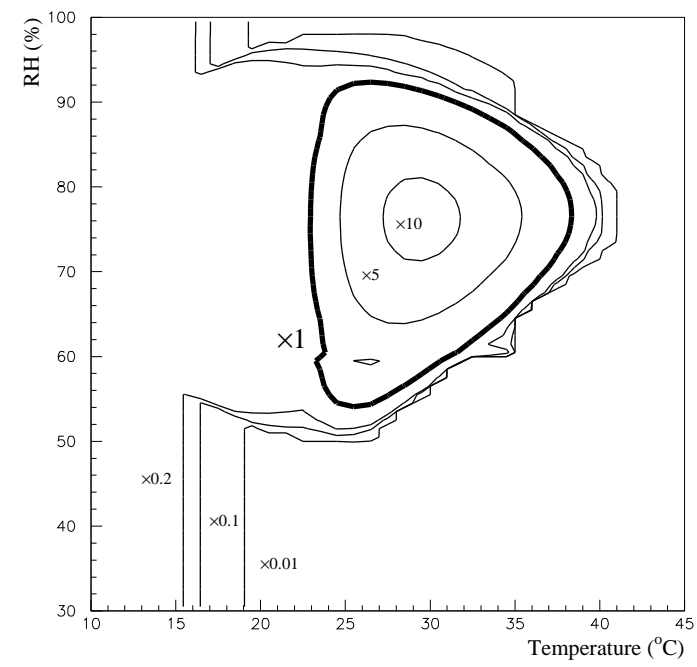

Figure 18 A contour plot of the complete mite population (eggs, juveniles and adults) growth factor after 30 days as predicted with the POPMITE model starting with 100 freshly laid eggs, for a range of relative humidity and temperature combinations 


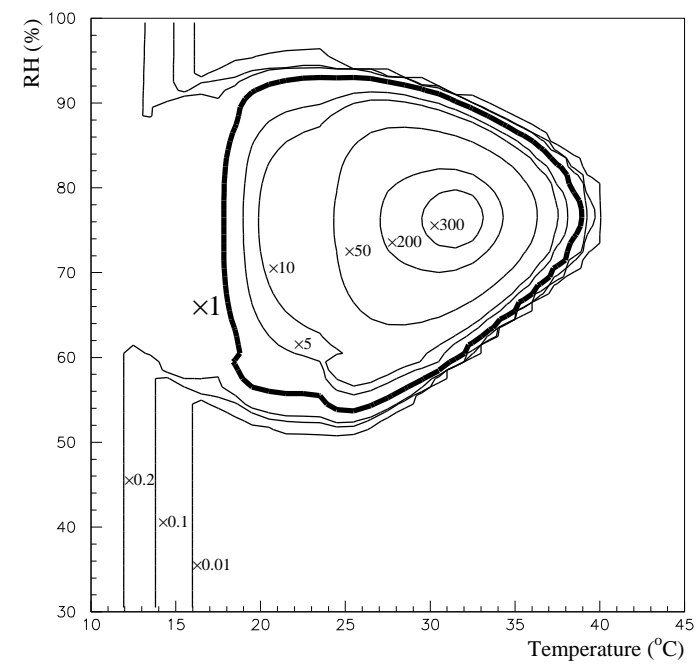

Figure 19 A contour plot of the complete mite population (eggs, juveniles and adults) growth factor after 60 days as predicted with the POPMITE model starting with 100 freshly laid eggs, for a range of relative humidity and temperature combinations 
Table 1 Development duration for Dermatophagoides Pteronyssinus (Acari: Pyroglyphidae) mite eggs in days, ${ }^{\mathrm{a} C o l l o f f}(1987 \mathrm{a}, 1987 \mathrm{~b}),{ }^{\mathrm{b}}$ Gamal Eddin et al. (1983b), ${ }^{\mathrm{c}}$ Arlian et al. (1990),

dSpieksma (1967)

\begin{tabular}{|c|c|c|c|c|c|c|c|c|c|c|c|c|c|c|c|c|c|}
\hline \multirow{3}{*}{$\begin{array}{c}\mathrm{RH}(\%) \\
50\end{array}$} & \multicolumn{17}{|c|}{ Temperature $\left({ }^{\circ} \mathrm{C}\right)$} \\
\hline & 10 & \multicolumn{2}{|c|}{15} & \multirow[t]{2}{*}{16} & \multicolumn{2}{|c|}{20} & \multirow[t]{2}{*}{23} & \multicolumn{3}{|c|}{25} & \multicolumn{2}{|c|}{30} & \multirow[t]{2}{*}{32} & \multicolumn{3}{|c|}{35} & \multirow[t]{2}{*}{40} \\
\hline & & & & & & & & & $16.2^{\mathrm{b}}$ & & & & & & & & \\
\hline 55 & $180^{\mathrm{a}}$ & $59^{\mathrm{a}}$ & & & $9.7^{\mathrm{a}}$ & & & $6.2^{\mathrm{a}}$ & $14^{\mathrm{b}}$ & & $5^{\mathrm{a}}$ & & & $4.2^{\mathrm{a}}$ & & & \\
\hline 60 & $155^{\mathrm{a}}$ & $42^{\mathrm{a}}$ & & & $9.2^{\mathrm{a}}$ & & & $6^{a}$ & $12.1^{\mathrm{b}}$ & & $4.8^{\mathrm{a}}$ & & & $4.2^{\mathrm{a}}$ & & & \\
\hline 65 & $120^{\mathrm{a}}$ & $37^{\mathrm{a}}$ & & & $9.1^{\mathrm{a}}$ & & & $5.8^{\mathrm{a}}$ & $10^{\mathrm{b}}$ & & $4.4^{\mathrm{a}}$ & & & $3.9^{\mathrm{a}}$ & & & \\
\hline 70 & $135^{\mathrm{a}}$ & $29^{\mathrm{a}}$ & & & $7.9^{\mathrm{a}}$ & & & $5.1^{\mathrm{a}}$ & $9.2^{\mathrm{b}}$ & & $4.1^{\mathrm{a}}$ & & & $4^{\mathrm{a}}$ & & & \\
\hline 75 & $145^{\mathrm{a}}$ & $32^{\mathrm{a}}$ & $19.3^{\mathrm{b}}$ & 26.6 & $7.9^{\mathrm{a}}$ & $12.2^{\mathrm{b}}$ & $8.1^{\mathrm{c}}$ & $4.5^{\mathrm{a}}$ & $8.3^{\mathrm{b}}$ & & $3.9^{\mathrm{a}}$ & $6.6^{\mathrm{b}}$ & $4.5^{\mathrm{c}}$ & $3.9^{\mathrm{a}}$ & $5.4^{\mathrm{b}}$ & $3.9^{\mathrm{c}}$ & $4^{b}$ \\
\hline 80 & $150^{\mathrm{a}}$ & $33^{\mathrm{a}}$ & & & $8^{\mathrm{a}}$ & & & $5^{\mathrm{a}}$ & $7.2^{\mathrm{b}}$ & $6^{\mathrm{d}}$ & $3.7^{\mathrm{a}}$ & & & $3.7^{\mathrm{a}}$ & & & \\
\hline 85 & $160^{\mathrm{a}}$ & $38^{\mathrm{a}}$ & & & $9^{a}$ & & & $5.2^{\mathrm{a}}$ & $8^{b}$ & & $4^{a}$ & & & $3.6^{\mathrm{a}}$ & & & \\
\hline 90 & $150^{\mathrm{a}}$ & $42^{\mathrm{a}}$ & & & $9.8^{\mathrm{a}}$ & & & $9^{a}$ & $10^{\mathrm{b}}$ & & $4^{a}$ & & & $3.5^{\mathrm{a}}$ & & & \\
\hline 95 & $150^{\mathrm{a}}$ & $44^{\mathrm{a}}$ & & & $9.5^{\mathrm{a}}$ & & & $5^{\mathrm{a}}$ & $14^{\mathrm{b}}$ & & $4.1^{\mathrm{a}}$ & & & $3.4^{\mathrm{a}}$ & & & \\
\hline 100 & $175^{a}$ & $45^{\mathrm{a}}$ & & & $10.5^{\mathrm{a}}$ & & & $5.2^{\mathrm{a}}$ & & & $4.2^{\mathrm{a}}$ & & & $3.9^{\mathrm{a}}$ & & & \\
\hline
\end{tabular}


Table 2 Total development time (days) of Dermatophagoides Pteronyssinus (Acari:

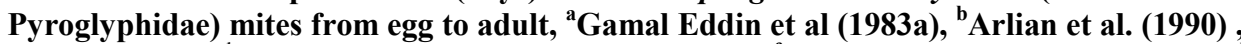
${ }^{c}$ Arlian (1975), ${ }^{d}$ Dobson (1979), ${ }^{\mathrm{e}}$ Hart and Fain (1988), ${ }^{\mathrm{f}}$ Blythe (1976), ${ }^{\mathrm{g}}$ Anderson (1988), ${ }^{\mathrm{h}}$ Ho and Nadchatram (1984), íSpieksma (1967)

\begin{tabular}{|c|c|c|c|c|c|c|c|c|c|c|c|c|c|c|c|c|}
\hline & \multicolumn{16}{|c|}{ Temperature $\left({ }^{\circ} \mathrm{C}\right)$} \\
\hline $\mathrm{RH}(\%)$ & 15 & 16 & \multicolumn{2}{|c|}{20} & 23 & \multicolumn{6}{|c|}{25} & \multicolumn{2}{|c|}{30} & \multicolumn{2}{|c|}{35} & 40 \\
\hline 50 & & & & & & $58^{\mathrm{a}}$ & & & & & & & & & & \\
\hline 55 & & & & & & $51^{\mathrm{a}}$ & & & & & & & & & & \\
\hline 60 & & & & & & $46.5^{\mathrm{a}}$ & & & & & & & & & & \\
\hline 65 & & & & & & $41.5^{\mathrm{a}}$ & & & & & & & & & & \\
\hline 70 & & & & & & $37.5^{\mathrm{a}}$ & & & & & & & & & & \\
\hline 75 & $95^{\mathrm{a}}$ & $123^{b}$ & 62.4 & $52^{\mathrm{a}}$ & $34^{b}$ & $36.5^{\mathrm{a}}$ & $14.3^{\circ}-x-x$ & $14.3^{\mathrm{e}}$ & $33^{\mathrm{f}}$ & $28^{\mathrm{h}}$ & & $19.3^{b}$ & $22.5^{\mathrm{a}}$ & $15^{\mathrm{b}}$ & $19.5^{\mathrm{a}}$ & $11^{\mathrm{a}}$ \\
\hline 80 & & & 45.3 & $45.2^{\mathrm{d}}$ & & $27^{a}$ & 18.3 & $16.7^{\mathrm{d}}$ & $13^{\mathrm{d}}$ & 23.68 & $23^{\mathrm{i}}$ & $16.6^{\mathrm{d}}$ & & $13^{\mathrm{d}}$ & & \\
\hline 85 & & & & & & $36.5^{\mathrm{a}}$ & & & & & & & & & & \\
\hline 90 & & & & & & $48^{\mathrm{a}}$ & & & & & & & & & & \\
\hline 95 & & & & & & $56^{\mathrm{a}}$ & & & & & & & & & & \\
\hline
\end{tabular}


Table 3 Adult longevity of Dermatophagoides Pteronyssinus (Acari:

Pyroglyphidae) mites (days), ${ }^{\mathrm{a} A r l i a n}$ (1975) and ${ }^{\mathrm{b}}$ Arlian et al. (1990).

\begin{tabular}{|c|c|c|c|c|c|}
\hline & \multicolumn{5}{|c|}{ Temperature $\left({ }^{\circ} \mathrm{C}\right)$} \\
\hline $\mathrm{RH}(\%)$ & 23 & 28 & 31 & 34 & 35 \\
\hline 40 & & $8^{\mathrm{a}}$ & $6^{\mathrm{a}}$ & $6^{\mathrm{a}}$ & \\
\hline 50 & & & $9^{\mathrm{a}}$ & $6^{\mathrm{a}}$ & \\
\hline 75 & $31.2^{\mathrm{b}}$ & & & & $15.5^{\mathrm{b}}$ \\
\hline
\end{tabular}


Table 4 Dermatophagoides Pteronyssinus (Acari: Pyroglyphidae) Egg mortality \% death at the end of the egg phase, ${ }^{a}$ Colloff $(1987 \mathrm{a}, 1987 \mathrm{~b}),{ }^{\mathrm{b}} \mathrm{Gamal}$ Eddin et al (1983b), ${ }^{\mathrm{c}}$ Spieksma (1967)

\begin{tabular}{|c|c|c|c|c|c|c|c|c|c|c|c|c|c|}
\hline & \multicolumn{9}{|c|}{ Temperature $\left.{ }^{\circ} \mathrm{C}\right)$} \\
\hline RH (\%) & 10 & \multicolumn{2}{|c|}{15} & \multicolumn{2}{|c|}{20} & \multicolumn{3}{|c|}{25} & \multicolumn{3}{|c|}{30} & \multicolumn{3}{|c|}{35} & 40 \\
\hline 50 & & & & & & & & $50^{\mathrm{b}}$ & & & & & \\
\hline 55 & $93^{\mathrm{a}}$ & $49^{\mathrm{a}}$ & & $62^{\mathrm{a}}$ & & $36^{\mathrm{a}}$ & & $38^{\mathrm{b}}$ & $48^{\mathrm{a}}$ & & $89^{\mathrm{a}}$ & & \\
\hline 60 & $98^{\mathrm{a}}$ & $41^{\mathrm{a}}$ & & $36^{\mathrm{a}}$ & & $36^{\mathrm{a}}$ & & $30^{\mathrm{b}}$ & $34^{\mathrm{a}}$ & & $69^{\mathrm{a}}$ & & \\
\hline 65 & $81^{\mathrm{a}}$ & $37^{\mathrm{a}}$ & & $26^{\mathrm{a}}$ & & $17^{\mathrm{a}}$ & & $12^{\mathrm{b}}$ & $15^{\mathrm{a}}$ & & $32^{\mathrm{a}}$ & & \\
\hline 70 & $92^{\mathrm{a}}$ & $35^{\mathrm{a}}$ & & $13^{\mathrm{a}}$ & & $13^{\mathrm{a}}$ & & $8^{\mathrm{b}}$ & $10^{\mathrm{a}}$ & & $24^{\mathrm{a}}$ & & \\
\hline 75 & $91^{\mathrm{a}}$ & $31^{\mathrm{a}}$ & $20^{\mathrm{b}}$ & $28^{\mathrm{a}}$ & $16^{\mathrm{b}}$ & $11^{\mathrm{a}}$ & $10^{\mathrm{b}}$ & $4^{\mathrm{b}}$ & $13^{\mathrm{a}}$ & $36^{\mathrm{b}}$ & $13^{\mathrm{a}}$ & $50^{\mathrm{b}}$ & $56^{\mathrm{b}}$ \\
\hline 80 & $90^{\mathrm{a}}$ & $17^{\mathrm{a}}$ & & $14^{\mathrm{a}}$ & & $30^{\mathrm{a}}$ & $45^{\mathrm{c}}$ & $10^{\mathrm{b}}$ & $26^{\mathrm{a}}$ & & $5^{\mathrm{a}}$ & & \\
\hline 85 & $79^{\mathrm{a}}$ & $21^{\mathrm{a}}$ & & $24^{\mathrm{a}}$ & & $15^{\mathrm{a}}$ & & $30^{\mathrm{b}}$ & $8^{\mathrm{a}}$ & & $5^{\mathrm{a}}$ & & \\
\hline 90 & $84^{\mathrm{a}}$ & $18^{\mathrm{a}}$ & & $14^{\mathrm{a}}$ & & $18^{\mathrm{a}}$ & & $50^{\mathrm{b}}$ & $16^{\mathrm{a}}$ & & $10^{\mathrm{a}}$ & & \\
\hline 95 & $85^{\mathrm{a}}$ & $23^{\mathrm{a}}$ & & $16^{\mathrm{a}}$ & & $17^{\mathrm{a}}$ & & $60^{\mathrm{b}}$ & $14^{\mathrm{a}}$ & & $13^{\mathrm{a}}$ & & \\
\hline 100 & $90^{\mathrm{a}}$ & $26^{\mathrm{a}}$ & & $19^{\mathrm{a}}$ & & $11^{\mathrm{a}}$ & & & $7^{\mathrm{a}}$ & & $15^{\mathrm{a}}$ & & \\
\hline
\end{tabular}


Table 5 Total egg to adult mortality of the Dermatophagoides Pteronyssinus (Acari: Pyroglyphidae) mite, Gamal Eddin et al. (1983a)

\begin{tabular}{|c|c|c|c|c|c|c|}
\hline & \multicolumn{6}{|c|}{ Temperature $\left({ }^{\circ} \mathrm{C}\right)$} \\
\hline RH(\%) & 15 & 20 & 25 & 30 & 35 & 40 \\
\hline 50 & & & 86 & & & \\
\hline 55 & & & 72 & & & \\
\hline 60 & & & 60 & & & \\
\hline 65 & & & 48 & & & \\
\hline 70 & & & 36 & & & \\
\hline 75 & 58 & 44 & 22 & 60 & 74 & 84 \\
\hline 80 & & & 18 & & & \\
\hline 85 & & & 50 & & & \\
\hline 90 & & & 72 & & & \\
\hline 95 & & & 86 & & & \\
\hline
\end{tabular}


Table 6 Mean number of eggs produced by a female Dermatophagoides Pteronyssinus (Acari:

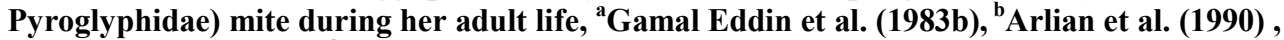
${ }^{c}$ Hart and Fain (1988), ${ }^{\mathrm{d}}$ Spieksma (1967).

\begin{tabular}{|c|l|l|l|c|c|c|c|c|c|}
\hline & \multicolumn{9}{|c|}{ Temperature $\left({ }^{\circ} \mathrm{C}\right)$} \\
\hline RH (\%) & 15 & 20 & 23 & \multicolumn{2}{|c|}{25} & 30 & \multicolumn{2}{|c|}{35} & 40 \\
\hline 50 & & & & $11^{\mathrm{a}}$ & & & & & \\
\hline 55 & & & & $23.7^{\mathrm{a}}$ & & & & & \\
\hline 60 & & & & $44.5^{\mathrm{a}}$ & & & & & \\
\hline 65 & & & & $70^{\mathrm{a}}$ & & & & & \\
\hline 70 & & & & $106^{\mathrm{a}}$ & & & & & \\
\hline 75 & $60^{\mathrm{a}}$ & $90.2^{\mathrm{a}}$ & $68.4^{\mathrm{b}}$ & $123^{\mathrm{a}}$ & $58.2^{\mathrm{c}}$ & $80^{\mathrm{a}}$ & $28^{\mathrm{a}}$ & $48^{\mathrm{b}}$ & $13.3^{\mathrm{a}}$ \\
\hline 80 & & & & $148^{\mathrm{a}}$ & $60^{\mathrm{d}}$ & & & & \\
\hline 85 & & & & $88.4^{\mathrm{a}}$ & & & & & \\
\hline 90 & & & & $10^{\mathrm{a}}$ & & & & & \\
\hline 95 & & & & $4^{\mathrm{a}}$ & & & & & \\
\hline
\end{tabular}

